University of Nebraska - Lincoln

DigitalCommons@University of Nebraska - Lincoln

USDA National Wildlife Research Center - Staff Publications
U.S. Department of Agriculture: Animal and Plant Health Inspection Service

January 2005

\title{
A comparison of three trap designs for capturing brown treesnakes on Guam
}

\author{
Daniel S. Vice \\ United States Department of Agriculture, Wildlife Services
}

Richard M. Engeman

USDA-APHIS-Wildlife Services, s_r100@yahoo.com

Diane L. Vice

United States Department of Agriculture, Wildlife Services, Guam Department of Agriculture, Division of Aquatic and Wildlife Resources

Follow this and additional works at: https://digitalcommons.unl.edu/icwdm_usdanwrc

Part of the Environmental Sciences Commons

Vice, Daniel S.; Engeman, Richard M.; and Vice, Diane L., "A comparison of three trap designs for capturing brown treesnakes on Guam" (2005). USDA National Wildlife Research Center - Staff Publications. 43.

https://digitalcommons.unl.edu/icwdm_usdanwrc/43

This Article is brought to you for free and open access by the U.S. Department of Agriculture: Animal and Plant Health Inspection Service at DigitalCommons@University of Nebraska - Lincoln. It has been accepted for inclusion in USDA National Wildlife Research Center - Staff Publications by an authorized administrator of DigitalCommons@University of Nebraska - Lincoln. 


\title{
A comparison of three trap designs for capturing brown treesnakes on Guam
}

\author{
Daniel S. Vice ${ }^{\mathrm{A}}$, Richard M. Engeman ${ }^{\mathrm{B}}$ and Diane L. Vice $\mathrm{A}^{\mathrm{A}, \mathrm{C}}$ \\ AUnited States Department of Agriculture, Wildlife Services, 1060 Route 16, \\ Suite 103C, Barrigada Heights, GU 96913, USA. \\ BNational Wildlife Research Center, 4101 LaPorte Avenue, Fort Collins, CO 80521, USA. \\ ${ }^{C}$ Current Address: Guam Department of Agriculture, Division of Aquatic and Wildlife Resources, \\ 192 Dairy Road, Mangilao, GU 96923, USA.
}

\begin{abstract}
The accidental introduction of the brown treesnake (Boiga irregularis) to Guam has resulted in the extirpation of most native terrestrial vertebrates on the island, thousands of power outages, and significant ecological changes. In addition, Guam now serves as a source population for the dispersal of snakes to other islands. Control of the brown treesnake is dependent upon the use of traps in a variety of settings, including port environments and in forested habitat. A variety of snake traps have been used on Guam; most consist of a modified crawfish or minnow trap, housing a live mouse that serves as a lure. We compared the efficacy of three trap styles: (1) a two-piece design with a separate internal mouse chamber; (2) a one-piece trap, with design improvements aimed at decreasing handling; and (3) the same one-piece trap, fitted with a PVC-coated wire-mesh entrance flap. Data collected included snake capture rates, snake size distribution, mouse survival, and trap maintenance time. Snake capture rates did not differ between the one-piece and the two-piece traps, although capture rates were significantly lower in the PVC-flap traps. The average snake size or distribution of snake sizes did not differ between the one-piece and two-piece traps. Handling times, both with and without a snake in the trap, were significantly lower for the one-piece trap. Mouse survival did not differ between the one-piece and two-piece trap styles. Our results indicate that the modified one-piece trap design provides several advantages over previous trap designs.
\end{abstract}

\section{Introduction}

Brown treesnakes (Boiga irregularis) were accidentally introduced to Guam via cargo shipments during the late 1940 s or early 1950 s. Over time, the snake population irrupted island-wide, reaching densities of up to 40 individuals per hectare $(=2.54$ acres $)$ of forest habitat and leading to the demise of most of the island's native avifauna and herpetofauna (Savidge 1987; Engbring and Fritts 1988), frequent power outages, and numerous human bites (Fritts 1988). Guam's importance as a trans-Pacific shipping hub, coupled with the tendency of snakes to seek refugia in cargo, make snake dispersal from Guam a serious threat to other island ecosystems (Fritts 1988; Fritts et al. 1999; Vice et al. 2003).

A primary means of controlling snakes is operational trapping, using trap designs constructed from modified minnow traps. Traps are effective for reducing snake populations in fragmented blocks of forest habitat characteristic of the island's ports of exit (Engeman and Linnell 1998; Engeman et al. 1998). Removal of snakes by means of traps, in support of both native species recovery and snake interdiction, has been successful in forest habitat blocks up to 20 ha in size (Campbell 1996; Anderson et al. 1998;
Engeman et al. 2000). When implemented, traps are hung on either forest vegetation or along security fences.

The development of an effective brown treesnake trap was instrumental to early wildlife-damage management efforts on Guam (Rodda et al. 1992). The first widely used traps were manufactured from two-piece crawfish or minnow traps, retrofitted with a one-way entrance on both funnels (Linnell et al. 1998; Rodda et al. 1999). The traps (herein referred to as $2 \mathrm{PC})$, constructed of $0.63-\mathrm{cm}\left(1 / 4^{\prime \prime}\right)$ hardware cloth, contain a half-moon or rectangular interior chamber that houses a live white mouse that serves as a lure (Rodda et al. 1999). Snakes entering the trap are unable to access the mouse and are subsequently removed from the trap by removing the trap from its attachment point(s) and opening the two sections. Replacing food and water source (a potato) for the mouse requires separating the two trap sections and pulling the interior chamber out of the trap.

The United States Department of Agriculture, Animal and Plant Health Inspection Service, Wildlife Services (WS) has used snake traps to remove snakes from Guam since 1993 (Vice and Pitzler 2002). During the initial development of the program, WS operations utilised the $2 \mathrm{PC}$ trap that was considered the current standard. As the control program 
expanded, improvements in trap-handling efficiency, durability and effectiveness became necessary. Feedback from field employees led to design improvements, most of which emphasised reduced handling time and ease of servicing while attempting to improve capture rates (Linnell et al. 1998). Numerous modifications occurred, until the current trap design was developed (herein referred to as the WS standard) (Fig. 1). The WS standard is a one-piece trap with a mouse chamber that is accessible from the exterior (i.e. mouse care can be performed without removing the trap from its site of attachment) (Fig. 2). The internal volume of the mouse chamber is $\sim 50 \%$ larger than the half-moon chamber used with the $2 \mathrm{PC}$ trap. Snakes are removed from the trap by opening a funnel on either end. Each funnel is fitted with a one-way entrance that will swing shut when the trap rotates about its horizontal axis (Linnell et al. 1998) (Fig. 2). The entrances are self setting and render the trap capable of multiple captures. Both the lure mouse and any captured snakes are protected from exposure to sun and moisture by a semi-rigid PVC cover, fitted over the top half of the trap.

The materials used in construction of the one-way entrances are important to both capture success and escape rates (Linnell et al. 1998; Rodda et al. 1999). Guam's climate is especially destructive to most metals: flaps made of hardware cloth quickly deteriorate in the high-salt and highhumidity environment characteristic of ports. Flaps constructed of plastic and corrosion-resistant metal have been tested, but most have not withstood damage from rats (Rattus spp.), hermit crabs (Coenobita spp.) and coconut crabs (Birgus latro), and may be held open during periods of heavy wind. To accommodate some of these concerns, a trap entrance that incorporated a hardware cloth flap coated with PVC (to slow or reduce corrosion) was designed (referred to as PVC-flap). In this experiment, we compared snake captures, including rate and size distribution, between the WS standard trap, the 2PC trap, and a WS standard trap fitted with the PVC flap. In addition, we compared mouse survival and trap-handling time between the WS standard trap and the
2PC trap. The PVC-flap trap was not included in mouse survival or handling-time evaluations, as the construction of the flap would not affect either factor.

\section{Materials and methods}

Study locations

We compared effectiveness of traps at 10 experimental locations on Guam (Table 1). We established trap lines along forest perimeters or fences on Andersen Air Force Base and Naval Communications Annex on the northern end of the island. Forest habitat generally consisted of native limestone forest, bounded by introduced Leucaena leucocephala trees (see Stone 1970 for a complete vegetative description of Guam). Fenceline sites were situated close to forest habitat (no more than $10 \mathrm{~m}$ from a forest edge). Each experiment was conducted in a different location, with snake abundance and microhabitat types inherently different at each site.

\section{Trap-evaluation methods}

We followed the guidelines on experimental design for optimally comparing traps set forth by Engeman and Vice (2001b). Each study location contained a single trap line, which consisted of equal numbers of alternating WS standard, 2 PC traps, and PVC-flap traps, except for the final two experiments, which included only WS standard and $2 \mathrm{PC}$ traps. We hung traps $\sim 1 \mathrm{~m}$ off the ground either directly on chain-link fences located close to forested habitat or in vegetation along the perimeter of forest plots. We spaced traps at 20-m intervals in both habitat types; the two hanging substrates were utilised, as both fences and forest edges serve as locations for operational trapping efforts (Vice and Pitzler 2002). Each trap contained a live white mouse, which served as a lure, and a 5-cm-diameter, $21-\mathrm{cm}$-long aluminum foil tube, which we used to indicate snake escapes (Linnell et al. 1998; Rodda et al. 1999).

Initially, we checked trap lines daily. After several weeks of daily data collection which indicated very low escape rates, we checked traps every 5-10 days, which reflects the operational standard of checking traps once every 7 days. Data collected from each line included the number of snakes captured, snake size (snout-vent length, SVL (mm)), condition of the mouse, frequency of foil tube crushes, and door failures (either stuck open or closed). Trap lines occasionally incurred human vandalism or damage from feral dogs (Canis familiaris) or feral pigs (Sus scrofa). Traps that were not operational when serviced were not included in capture or trap-night calculations.

We evaluated trap-handling times using traps hung at chest height on a chain-link fence. For each set of handling times, a randomly 


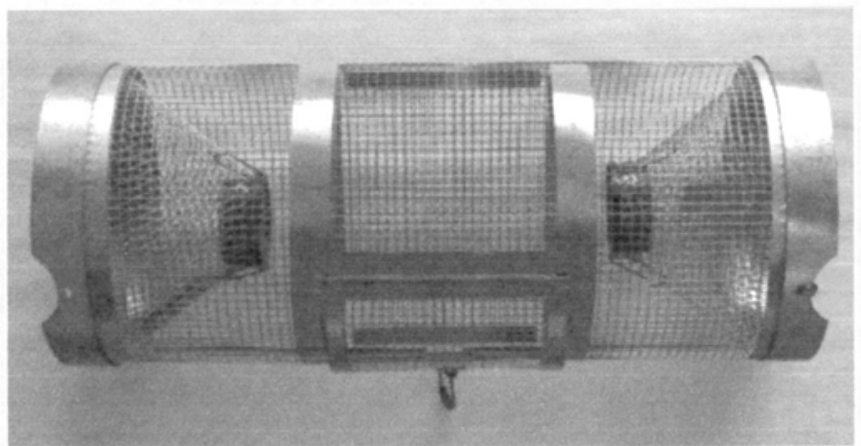

Fig. 1. The WS standard brown treesnake trap, fully assembled, top view. The centre of the trap houses the mouse chamber, with the entrance door visible in the bottom centre of the photograph.

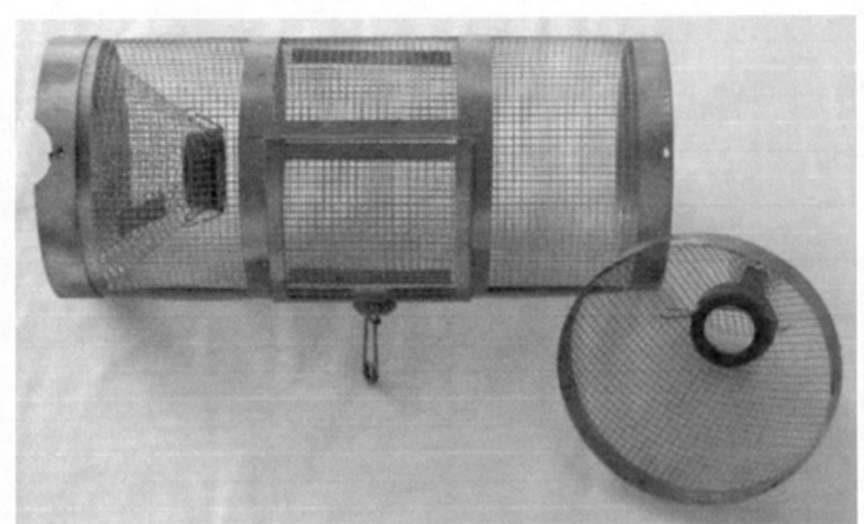

Fig. 2. The WS standard brown treesnake trap, showing one removable funnel and one-way flap entrance (right side), as well as the external door to the mouse chamber. 
Table 1. Trapping success data and average size of brown treesnakes captured in three different traps in two habitat types

SVL, snout-vent length

\begin{tabular}{llccccc}
\hline Trap & Habitat & $\begin{array}{c}\text { No. of } \\
\text { captures }\end{array}$ & $\begin{array}{c}\text { No. of } \\
\text { trap-nights }\end{array}$ & $\begin{array}{c}\text { No. of captures } \\
\text { per trap-night }\end{array}$ & $\begin{array}{c}\text { Mean SVL } \\
(\mathrm{mm})\end{array}$ & s.e.m. \\
\hline WS standard & Fence & 127 & 2085 & 0.06 & 918.5 & 13.6 \\
WS standard & Forest & 80 & 919 & 0.09 & 963.1 & 15.1 \\
2PC & Fence & 96 & 1949 & 0.05 & 945.6 & 14.0 \\
2PC & Forest & 55 & 952 & 0.06 & 922.4 & 18.0 \\
PVC-flap & Fence & 46 & 1524 & 0.03 & 977.1 & 17.5 \\
PVC-flap & Forest & 38 & 873 & 0.04 & 956.0 & 18.8 \\
WS standard & Overall & 207 & 3004 & 0.06 & 940.8 & 10.2 \\
2PC & Overall & 151 & 2901 & 0.05 & 934.0 & 11.4 \\
PVC-flap & Overall & 84 & 2397 & 0.03 & 966.5 & 12.9 \\
\hline
\end{tabular}

selected, full-time snake-trapping technician, with substantial field experience operating both one-piece and two-piece traps, was presented with four trap scenarios: (1) WS Standard trap without a snake; (2) 2 PC trap without a snake; (3) WS Standard trap with a snake; and (4) 2 PC trap with a snake. The technician was timed as he or she replaced the food block and potato in the two no-snake trap scenarios as well as replacing the food block and potato and removing the snake in the two trap scenarios containing snakes. Snakes were placed in traps and allowed sufficient time to assume the coiled resting posture they typically maintain when confined. Ten trials were run, using two different experienced trap operators, at five trials each. Both operators were assumed to be equal in ability.

\section{Statistical methods}

We used two-factor repeated-measures mixed linear model design (e.g. McLean et al. 1991; Wolfinger et al. 1991) to analyse trap capture rates and snake lengths, where trap lines characterised by the location and time of their placement defined blocks of repeated treatments (trap design factor) nested in each of the habitat types.

We analysed trap-handling times as a two-factor repeated-measures type of mixed model, but with both trap type and snake presence (or not) as repeated factors for each subject (operator). We used SAS PROC MIXED with a restricted maximum-likelihood estimation procedure (REML) for the analyses (SAS Institute 1992, 1996, 1997). We analysed mouse survival times non-parametrically using Kaplan and Meier (1958) survival analyses followed by Wilcoxon comparisons of survival curves among trap types (Kalbfleish and Prentice 1980). We used SAS PROC LIFETEST to conduct the analyses (SAS Institute 1996).

\section{Results}

\section{Catch rates}

The three trap types had different capture rates, with the PVC-flap traps capturing fewer snakes than the other two trap types $\left(F_{2,12}=3.95, P=0.048\right.$; Table 1$)$. Escape rates for all trap types were judged to be too low to warrant further investigation. No other species were captured in the traps during the experiment.

\section{Size comparisons}

The size distribution of snakes captured in the WS standard and 2 PC traps were similar (Fisher's 'exact' test, $P=0.496$ ) (Fig. 3). Differences were found in average snake size among the means of the trap-by-habitat interaction $\left(F_{1,6}=5.27\right.$, $P=0.06$ ) (Fig. 3), with the WS standard capturing larger snakes from the fence and the 2PC capturing larger snakes from the forest. Only limited biological inferences can be drawn from these results, as the four means are still within $4 \%$ of each other. The mean size of forest-caught snakes was larger for the WS standard, but averaged smaller for the 2PC. Over both habitats combined, no difference was detected between mean sizes for snakes caught with the WS standard trap or the $2 \mathrm{PC}$ trap $\left(F_{1,6}=0.21, P=0.663\right)$.

\section{Mouse survival}

The percentage of mice surviving the duration of the experiment did not differ between WS standard traps and 2PC traps when habitat was considered or when habitats were combined (Table 2).

\section{Trap maintenance}

The WS standard required less time to maintain than the $2 \mathrm{PC}$, both with and without a snake $\left(F_{1,8}=6.12, P=0.039\right)$. The $2 \mathrm{PC}$ took 3 times longer $(47.8 \pm 9.6 \mathrm{~s}$ versus $16.9 \pm 1.0 \mathrm{~s})$

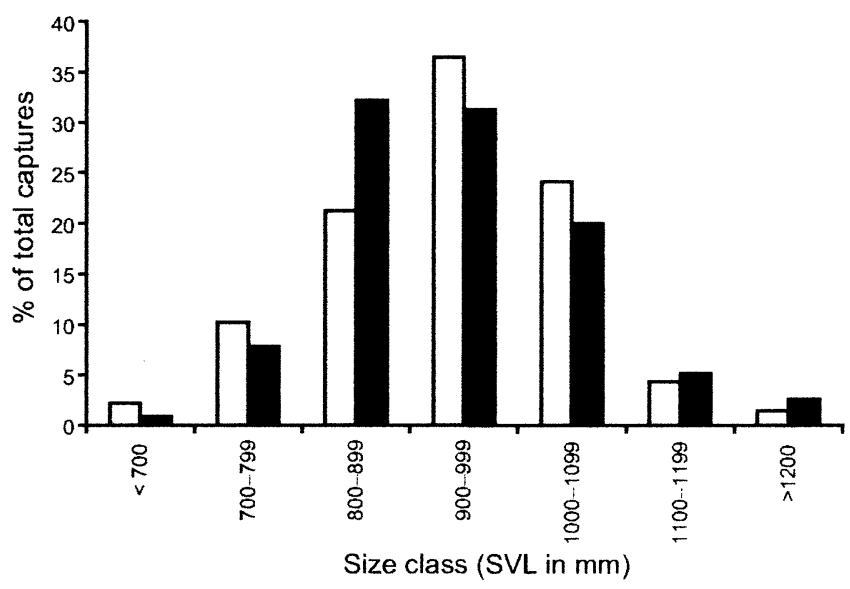

Fig. 3. Size distribution of brown treesnakes captured using two different trap types. 
than the WS standard without a snake, but only 1.2 times as long $(70.6 \pm 5.3 \mathrm{~s}$ versus $60.3 \pm 3.5 \mathrm{~s})$ with a snake.

\section{Discussion}

Expanding brown treesnake control programs have facilitated the need for traps that are efficient to operate as well as effective at capturing snakes. An effective brown treesnake trap must be robust to differential snake densities, environmental variability, and human disturbances. This evaluation was structured to mirror the variability in snake capture success and habitat that occur in large-scale control operations against brown treesnakes on Guam. Trap improvements allow snake-control personnel to operate larger numbers of traps in less time, thereby increasing the efficiency of control efforts and ultimately reducing the cost per snake removed. The WS standard trap captures snakes at a rate comparable to previously available traps while reducing maintenance time. The primary improvements are the exterior-opening mouse chamber, which decreases the amount of time needed to replace the food and water source for the mouse, and the removable funnels, which reduce the time necessary for removing snakes from the trap. These improvements, in turn, allow greater trap coverage with reduced additional effort. Continued refinements in other areas of brown treesnake trapping, including the development of an effective inanimate lure, would further enhance trap efficiency.

In addition to minimal handling time, an effective trap should capture a wide size distribution of snakes in a variety of habitats and across all seasons. Considerable emphasis has been placed on the biases of snake traps towards the capture of medium-sized snakes (Rodda et al. 1999). Neither trap design captured snakes less than $700 \mathrm{~mm}$ SVL regularly. However, it is difficult to consistently capture very small brown treesnakes using any method, and therefore, it is difficult to assess size distributions within a given snake population and the subsequent meaning of size distributions captured by any method. Since many snakes encountered in and around cargo facilities are less than $800 \mathrm{~mm}$ SVL (Vice and Vice 2004) and numerous snakes captured off Guam have been of similar size (Fritts et al. 1999), continued research exploring ways to detect and capture very small snakes is necessary.

Table 2. Mouse survival, expressed as a percentage surviving the duration of the experiment, in two different brown treesnake trap types

\begin{tabular}{lcccc}
\hline Trap type & Habitat & Survival (\%) & s.e.m. & $P$ \\
\hline WS standard & Fence & 88.0 & 6.5 & 0.64 \\
2PC & Fence & 81.5 & 7.5 & \\
WS standard & Forest & 93.3 & 7.5 & 0.37 \\
2PC & Forest & 82.4 & 9.2 & \\
WS standard & Overall & 90.0 & 4.7 & 0.37 \\
2PC & Overall & 81.8 & 5.8 & \\
\hline
\end{tabular}

Large snakes ( $>1200 \mathrm{~mm} \mathrm{SVL})$ were also infrequently caught. Large snakes are frequently caught when trapping in commensal situations on Guam, where endothermic prey (i.e. rats and introduced birds) are more prevalent. The lack of captures of large snakes in this study may be partially explained by the sites selected. All trap lines were located adjacent to large blocks of forest, which had minimal adjacent human development and low populations of introduced rodents and birds.

Trap placement on the perimeter of forest blocks has been demonstrated to be an effective and efficient method for removing snakes (Engeman et al. 1998). In areas where trap security is a concern or where there are no forest edges available, traps placed on fences are effective at capturing snakes (Engeman and Vice 2001a). Many port environments are surrounded by chain-link fences, which support trapping efforts and provide security from theft and/or vandalism. In addition, supplemental traps placed on port perimeter fences may capture snakes that have circumvented trap lines situated along adjacent forest edges.

The PVC-flap traps captured a smaller distribution of snake sizes than the other two trap types. This difference can be attributed to the lower capture rates found for the PVCflap trap, which may have several explanations. Changes in flap weight, even very small differences, may impact the rate at which snakes will enter a trap. The PVC-coated flaps weighed $\sim 1 \mathrm{~g}$ more than the regular wire-mesh flaps, which may adversely impact entrance rates. Second, the edges of the flap often caught on the reducing washer that forms the trap entrance; the result was not a stuck flap, but rather a flap that required greater initial force to open. Additional smoothing along the flap edges may eliminate the second problem and warrants further investigation.

Mouse survival was high for both trap types. Monitoring survival over a longer period may detect differences in survival between the traps. However, unpublished trapping data (D. S. Vice) suggest that an important factor affecting mouse survival in traps is the condition of the mouse prior to being placed in the trap. Full-grown, healthy mice exhibit lower mortality in traps than juveniles or mice in poor health. Until an inanimate replacement for the live mouse is discovered, monitoring and improving the survival of lure mice is a critical component of future trapping research.

Traps serve as part of a larger integrated wildlife-damage management approach to brown treesnake control on Guam (Vice and Pitzler 2002; Vice et al. 2003). Although traps effectively capture snakes, additional control techniques such as hand capture (Engeman and Vice 2001a) and detector dogs (Vice and Engeman 2001) are critical components of efforts to reduce snake populations and to prevent their dispersal from Guam (Vice and Vice 2004). Once snake populations have been locally depleted, reducing the rate of snake immigration is necessary. Traps may provide some level of protection against reinvasion, but do not serve as an 
impermeable barrier. The addition of the oral toxicant acetaminophen (Savarie et al. 2001), now registered for operational use, and permanent barriers (Perry et al. 1998) will enhance snake-control capabilities and may provide an additional layer of protection against snake reinvasion.

\section{Acknowledgments}

We thank E. W. Campbell III., C. S. Clark, L. Clark, J. A. Lynch, M. E. Pitzler, P. J. Savarie and two anonymous reviewers for their helpful comments on this manuscript. This project was conducted under funding provided to the USA Department of Agriculture, Animal and Plant Health Inspection Service, Wildlife Services, Washington State Director's Office, by the USA Department of Defence, under DOD MIPR-064-95, 'Operational Control of Brown Tree Snakes in Guam'.

\section{References}

Anderson, R. D., Beauprez, G. M., and Searle, A. D. (1998). Creation of a snake-free area on Guam using trapping and barrier technology. In 'Brown Treesnake Research Symposium. Honolulu, HI'. http://www.fort.usgs.gov/conferences/bts/abstracts.asp

Campbell, E. W., III. (1996). The effect of brown tree snake (Boiga irregularis) predation on the island of Guam's extant lizard assemblages. Ph.D. Thesis, Ohio State University, Columbus.

Engbring, J., and Fritts, T. H. (1988). Demise of an insular avifauna: the brown treesnake on Guam. Transactions of the Western Section of the Wildlife Society 24, 31-37.

Engeman, R. M., and Linnell, M. A. (1998). Trapping strategies for deterring the spread of brown treesnakes from Guam. Pacific Conservation Biology 4, 348-353.

Engeman, R. M., and Vice, D. S. (2001a). A direct comparison of trapping and spotlight searches for capturing brown tree snake on Guam. Pacific Conservation Biology 7, 4-8.

Engeman, R. M., and Vice, D. S. (2001b). Standardizing the evaluation of brown tree snake traps. Integrated Pest Management Reviews 5 , 205-212. doi:10.1023/A:1011324229980

Engeman, R. M., Sayama, S., and Linnell, M. A. (1998). Operational utility of perimeter trapping for removing brown tree snakes (Boiga irregularis) from a defined area. Snake 28, 19-22.

Engeman, R. M., Vice, D. S., Nelson, G., and Muña, E. (2000). Brown tree snakes effectively removed from a large plot of land on Guam by perimeter trapping. International Biodeterioration \& Biodegradation 45, 139-142. doi:10.1016/S0964-8305(00)00039-1

Fritts, T. H. (1988). The brown tree snake, Boiga irregularis, a threat to Pacific islands. U.S. Department of Interior Biological Report No. 88.

Fritts, T. H., McCoid, M. J., and Gomez, D. M. (1999). Dispersal of snakes to extralimital islands: incidents of the brown treesnake, Boiga irregularis, dispersing to islands in ships and aircraft. In 'Problem Snake Management: the Habu and the Brown Treesnake'. (Eds G. H. Rodda, Y. Sawai, D. Chizar and H. Tanaka.) pp. 209-223. (Cornell University Press: Ithaca, NY.)
Kalbfleish, J. D., and Prentice, R. L. (1980). 'The Statistical Analysis of Failure Time Data.' (John Wiley and Sons: New York.)

Kaplan, E. L., and Meier, P. (1958). Nonparametric estimation from incomplete observations. Journal of the American Statistical Association 53, 457-481.

Linnell, M. A., Engeman, R. M., Pitzler, M. E., Watton, M. O., Whitehead, G. F., and Miller, R. C. (1998). An evaluation of two designs of stamped metal trap flaps for use in operational trapping of brown treesnakes (Boiga irregularis). Snake 28, 14-18.

McLean, R. A., Sanders, W. L., and Stroup, W. W. (1991). A unified approach to mixed linear models. American Statistician 45, 54-64.

Perry, G., Campbell, E. W., III, Rodda, G. H., and Fritts, T. H. (1998). Managing island biotas: brown treesnake control using barrier technology. In 'Vertebrate Pest Conference No. 18'. pp. 138-143.

Rodda, G. H., Rondeau, R. J., Fritts, T. H., and Maughan, O. E. (1992). Trapping the arboreal snake Boiga irregularis. Amphibia-Reptilia $13,47-56$.

Rodda, G. H., Fritts, T. H., Clark, C. S., Gotte, S. W., and Chizar, D. (1999). A state-of-the-art trap for the brown treesnake. In 'Problem Snake Management: the Habu and the Brown Treesnake'. (Eds G. H. Rodda, Y. Sawai, D. Chizar, and H. Tanaka.) pp. 268-305. (Cornell University Press: Ithaca, NY.)

SAS Institute (1992). 'SAS Technical Report P-229 SAS/STAT Software: Changes and Enhancements.' (SAS Institute: Carey, NC.)

SAS Institute (1996). 'SAS/STAT User's Guide.' (SAS Institute: Carey, NC.)

SAS Institute (1997). 'SAS/STAT - Software Changes and Enhancements through Release 6.12.' (SAS Institute: Carey, NC.)

Savarie, P. J., Shivik, J. A., White, G. C., Hurley, J. C., and Clark, L. (2001). Large scale control of brown treesnakes using acetaminophen. Journal of Wildlife Management 65, 356-365.

Savidge, J. A. (1987). Extinction of an island forest avifauna by an introduced snake. Ecology 68, 660-668.

Stone, B. C. (1970). The flora of Guam. Micronesica 6, 1-659.

Vice, D. S., and Engeman, R. M. (2001). Brown treesnake discoveries during detector $\operatorname{dog}$ inspections following Supertyphoon Paka. Micronesica 33, 105-110.

Vice, D. S., and Pitzler, M. E. (2002). Brown treesnake control: economy of scales. In 'Human Conflicts with Wildlife: Economic Considerations'. (Ed. L. Clark) pp. 127-131. (National Wildlife Center: Fort Collins, CO.)

Vice, D. S., and Vice, D. L. (2004). Characteristics of brown treesnakes removed from Guam's transportation network. Pacific Conservation Biology 10, 216-221.

Vice, D. S., Linnell, M. A., and Pitzler, M. E. (2003). Draft summary of Guam's outbound cargo handling process: preventing the spread of the brown treesnake. U.S. Department of Agriculture, Animal and Plant Health Inspection Service, Wildlife Services, Barrigada, Guam.

Wolfinger, R. D., Tobias, R. D., and Sall, J. (1991). Mixed models: a future direction. In ' 16 th SAS Users Group Conference'. (Ed. M. Rosenberg.) pp. 1380-1388. (SAS Institute: Cary, NC.)

Manuscript received 26 May 2004, accepted 19 April 2005 